\title{
Presentation of an experimental method to induce in vitro ("organ chambers") respiratory acidosis and its effect on vascular reactivity ${ }^{1}$
}

\author{
Tales Rubens de Nadai, Ana Paula Cassiano Silveira ${ }^{\text {II }}$, Ariadne Santana e Neves Monteiro" ${ }^{\text {II }}$ Debora Ribeiro Campos ${ }^{\text {II }}$, Marco \\ Tulio Rezende de Carvalho ${ }^{\text {II }}$, Agnes Afrodite Sumarelli Albuquerque ${ }^{\text {II }}$, Andrea Carla Celotto ${ }^{\text {III }}$, Paulo Roberto Barbosa Evora ${ }^{\text {IV }}$ \\ DOI: http://dx.doi.org/10.1590/S0102-86502014001800003 \\ IFellow PhD degree, Experimental Medicine Program, Division of Thoracic and Cardiovascular Surgery, Department of Surgery and Anatomy, Ribeirao \\ Preto School of Medicine, University of Sao Paulo (FMRP-USP), Brazil. Conception and design of the study, manuscript writing. \\ IIFellow Master degree, Experimental Medicine Program, Division of Thoracic and Cardiovascular Surgery, Department of Surgery and Anatomy, \\ FMRP-USP, Ribeirao Preto-SP, Brazil. Acquisition of data. \\ IIIFellow PhD degree, Experimental Medicine Program, Division of Thoracic and Cardiovascular Surgery, Department of Surgery and Anatomy, \\ FMRP-USP, Ribeirao Preto-SP, Brazil. Conception and design of study, manuscript writing, critical revision. \\ ${ }^{\text {IV }} \mathrm{PhD}$, Full Professor, Division of Thoracic and Cardiovascular Surgery, Department of Surgery and Anatomy, FMRP-USP, Ribeirao Preto-SP, Brazil. \\ Conception and design of the study, manuscript writing, critical revision.
}

\begin{abstract}
PURPOSE: To create in vitro a model to generate acidosis by $\mathrm{CO}_{2}$ bubbling "organ chambers", which would be useful for researchers that aim to study the effects of acid-base disturbs on the endothelium-dependent vascular reactivity.

METHODS: Eighteen male Wistar rats (230-280g) were housed, before the experiments, under standard laboratory conditions (12h light/ dark cycle at $21^{\circ} \mathrm{C}$ ), with free access to food and water. The protocol for promoting in vitro respiratory acidosis was carried out by bubbling increased concentrations of $\mathrm{CO}_{2}$. The target was to achieve an ideal way to decrease the $\mathrm{pH}$ gradually to a value of approximately 6.6.It was used, initially, a gas blender varying concentrations of the carbogenic mixture $\left(95 \% \mathrm{O}_{2}+5 \% \mathrm{CO}_{2}\right)$ and pure $\mathrm{CO}_{2}$.

RESULTS: 1) $100 \% \mathrm{CO}_{2}, \mathrm{pH}$ variation very fast, $\mathrm{pH}$ minimum 6.0 ; 2) $90 \% \mathrm{CO}_{2} \mathrm{pH}$ variation bit slower, $\mathrm{pH}$ minimum6.31; 3) 70\%CO $\mathrm{pH}$ variation slower, $\mathrm{pH}$ minimum 6.32; 4) 50\% $\mathrm{CO}_{2}, \mathrm{pH}$ variation slower, $\mathrm{pH}$ minimum 6:42; 5) $40 \% \mathrm{CO}_{2}, \mathrm{Adequate}$ record, $\mathrm{pH}$ minimum 6.61, and; 6) $30 \% \mathrm{CO}_{2}$ could not reach values below $\mathrm{pH}$ minimum 7.03. Based on these data the gas mixture $\left(\mathrm{O}_{2} 60 \%+\mathrm{CO}_{2}\right.$ 40\%) was adopted,
\end{abstract}

CONCLUSION: This gas mixture $\left(\mathrm{O}_{2} 60 \%+\mathrm{CO}_{2} 40 \%\right)$ was effective in inducing respiratory acidosis at a speed that made, possible the recording of isometric force.

Key words: Acidosis, Respiratory. Endothelium. Nitric Oxide. Rats. 


\section{Introduction}

Acid-base shifts are caused by $\mathrm{pCO}_{2}$ changes (respiratory mechanisms) and addition of acid or base (non-respiratory mechanisms).These shifts affect the vascular reactivity, and, besides the direct effect on vascular tone, may also alter vascular vasoconstrictor and/or vasodilatorsresponsiveness ${ }^{1-3}$.

This study proposes to develop a method in which acidosis is induced in vitro by bubbling $\mathrm{CO}_{2}$ in Krebs solution ("organ chambers" bath), in adequate interval of time to record the changes in isometric force. In other words, the present study was carried out to create an in vitro model to generate acidosis by $\mathrm{CO}_{2}$ bubbling "organ chambers", which would be useful for researchers that aim to study the effects of acid-base disturbs on the endothelium-dependent vascular reactivity.

\section{Methods}

The experimental procedures and animal handling were reviewed and approved by the Institutional Animal Care Review Board (CETEA - Ethics Committees of Animal Experiments of the Ribeirao Preto School of Medicine, University of Sao Paulo. This investigation conforms to the Guide for the Care and Use of Laboratory Animals published by the US National Institutes of Health (NIH Publication No. 85-23, revised 1996).

Eighteen male Wistar rats (230-280 g) were housed, before the experiments, under standard laboratory conditions $(12 \mathrm{~h}$ light/dark cycle at $21^{\circ} \mathrm{C}$ ), with free access to food and water.

The rats were anesthetized with isoflurane, followed by a laparotomy for exsanguination via abdominal aorta and a thoracotomy for thoracic aorta harvesting. The thoracic aorta was carefully dissected free of connective tissue and immediately immersed in Krebs or Hanks solution. For the vascular reactivity studies, Krebs solution with the following composition (mM) was employed: $\mathrm{NaCl}$ - 118.0, $\mathrm{KCl}$ - 4.7, $\mathrm{CaCl}_{2}-2.5, \mathrm{KH}_{2} \mathrm{PO}_{4}-1.2, \mathrm{MgSO}_{4}-1.66$, glucose - 11.1, $\mathrm{NaHCO}_{3}-25.0$ (pH 7.4).

The thoracic aorta was cut into rings (4-5 $\mathrm{mm}$ in length). The endothelium was removed from some rings by gently rubbing the intimal surface of the blood vessel with a pair of watchmaker's forceps. This procedure removes the endothelium, but it does not affect the ability of the vascular smooth muscle to contract or relax. Then, these rings were placed in isolated organ baths $(10 \mathrm{~mL})$ filled with Krebs solution, maintained at $37^{\circ} \mathrm{C}$ and bubbled with $95 \% \mathrm{O}_{2} / 5 \%$ $\mathrm{CO}_{2}$ (pH 7.4). Each arterial ring was suspended by two stainless steel clips placed through the lumen. One clip was anchored to the bottom of the organ bath while the other was connected to a strain gauge for measurement of the isometric force with the aid of the Grass FT03 equipment (Grass Instrument Company, Quincy, MA, USA). Each ring was stretched to a resting tension of $1.5 \mathrm{~g}$ and allowed to equilibrate for $60 \mathrm{~min}$. During this period, tissues were washed every 15 minutes. By means of a pilot study, the resting tension value was determined by construction of a curve expressing contraction (in response to $\mathrm{KCl} 45 \mathrm{mM}$ ) per tension (given by progressive ring stretching). The tension value that evoked the maximal contraction was elected as the optimal length-tension. The efficacy of the procedure for endothelium removal was confirmed by the lack of relaxant effects induced by acetylcholine $\left(10^{-6} \mathrm{M}\right)$ in rings pre-contracted with Phe $\left(10^{-6} \mathrm{M}-\mathrm{EC}_{80}\right)$. Endothelium was considered to be present when the Ach-induced relaxation was at least $80 \%$. Endothelium was deemed absent when its response was not developed. Then, each ring was washed and re-equilibrated for 30 minutes. Aortic rings were then precontracted with Phe $\left(10^{-6} \mathrm{M}\right)$, and $\mathrm{pH}$-response curves were obtained after a stable plateau was reached.

The protocol for promoting in vitro respiratory acidosis was carried out by bubbling increased concentrations of $\mathrm{CO}_{2}$. The target was to achieve an ideal way to decrease the $\mathrm{pH}$ gradually to a value of approximately 6.6.It was used, initially, a gas blender varying concentrations of the carbogenic mixture $\left(95 \% \mathrm{O}_{2}+5 \% \mathrm{CO}_{2}\right)$ and pure $\mathrm{O}_{2}$ (Figure 1$)$.

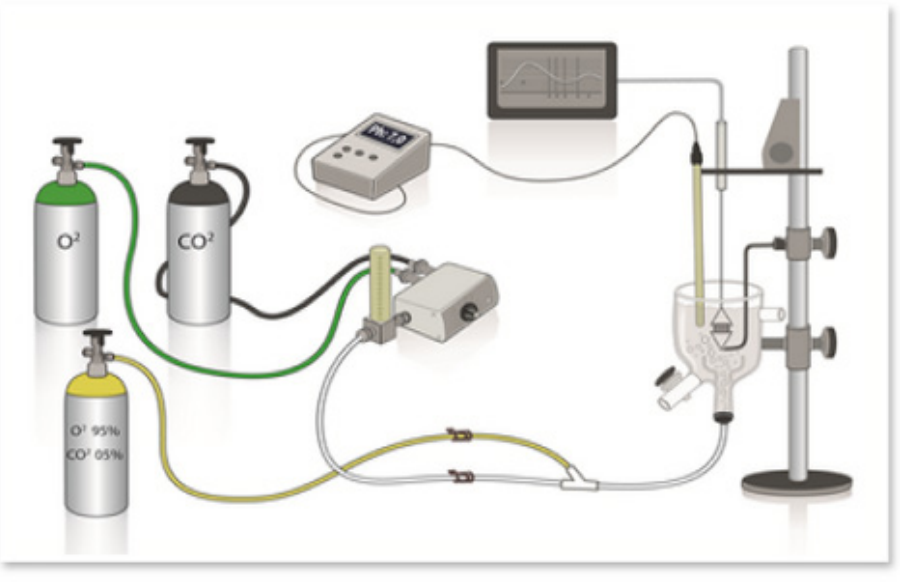

FIGURE 1 - Schematic experimental setting up test the gas concentrations.

\section{Results}

The test results are shown in Tables 1 and 2. 
TABLE 1 - Test bubbling $\mathrm{CO}_{2}$ in the Krebs solution at $37^{\circ} \mathrm{C}$ temperature. The gas mixture containing $40 \% \mathrm{CO}_{2}$ and $60 \%$ $\mathrm{O}_{2}$ was sufficient to shift the $\mathrm{pH}$ from 7.5 to 6.6 gradually.

\begin{tabular}{ccc}
\hline \multicolumn{4}{c}{$\mathbf{\%} \mathbf{C O}_{\mathbf{2}}$ rating $\mathbf{p H}$ variation $\mathbf{p H}$ minimum } \\
\hline 100 & Very Fast & 6.00 \\
90 & Bit slower & 6.31 \\
70 & Slower & 6.32 \\
50 & Slower & 6.42 \\
40 & Adequate record & 6.61 \\
30 & Could not reach values below & 7.03 \\
\hline
\end{tabular}

TABLE 2 - Values of blood gases in samples of Krebs harvested at the lowest $\mathrm{pH}$ achieved by mixing $\mathrm{CO}_{2} / \mathrm{O}_{2}-40 / 60$.

\begin{tabular}{cccc}
\hline Sample & $\mathbf{p H}$ & $\mathbf{p O}_{\mathbf{2}} \mathbf{~ m m H g}$ & $\mathbf{p C O}_{\mathbf{2}} \mathbf{~ m m H g}$ \\
\hline $1^{\mathrm{a}}$ & 6.88 & 421.4 & 118.8 \\
$2^{\mathrm{a}}$ & 6.86 & 437.7 & 122.0 \\
$3^{\mathrm{a}}$ & 6.77 & 423.1 & 152.8
\end{tabular}

With these results, it was decided to test a commercially ready, with a cylinder gas mixture produced by the company Praxair with $40 \% \mathrm{CO}_{2}$ and $60 \% \mathrm{O}_{2}$ to start the experiment protocols reactivity (Figure 2). This gas mixture was effective in inducing respiratory acidosis at a speed that made possible the recording of isometric force (Figure 2). The final experimental setting up is presenting in Figure 3.

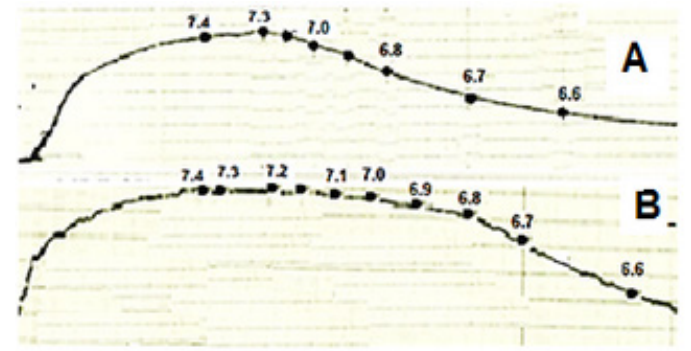

FIGURE 2 - Representative image of a pH-response curves in isolated rat aorta with endothelium (A) and without endothelium (B) with Phe pre-contracted rings. The curve was produced by bubbling $\mathrm{CO}_{2}$ in a mixture $40 / 60$ with $\mathrm{O}_{2}$ and $\mathrm{pH}$ drop was annotation every 0.1 unit. The pre-contraction was induced with Phe $\left(10^{-6} \mathrm{M}\right)$.

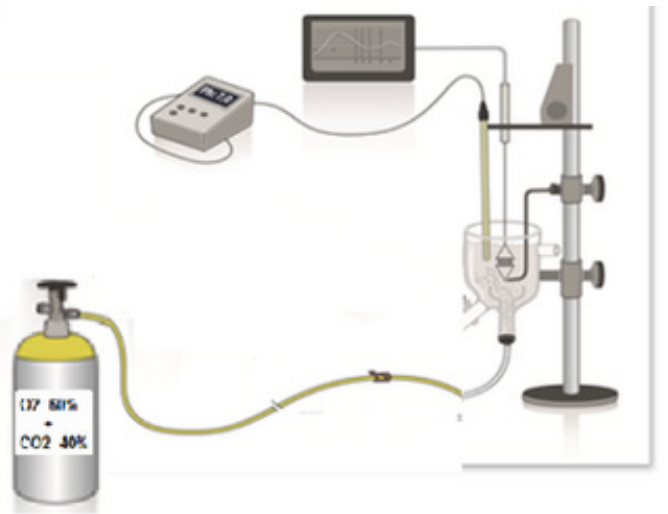

FIGURE 3 - Final experimental setting up $\left(\mathrm{O}_{2} 60 \%+\mathrm{CO}_{2} 40 \%\right)$.
After characterizing the vascular profile triggered by the change of $\mathrm{pH}$ (Figure 3), it was investigated the three endothelium-dependent mechanisms (cGMP/NO, AMPc/PGI 2 and hyperpolarization) (Figure 4).

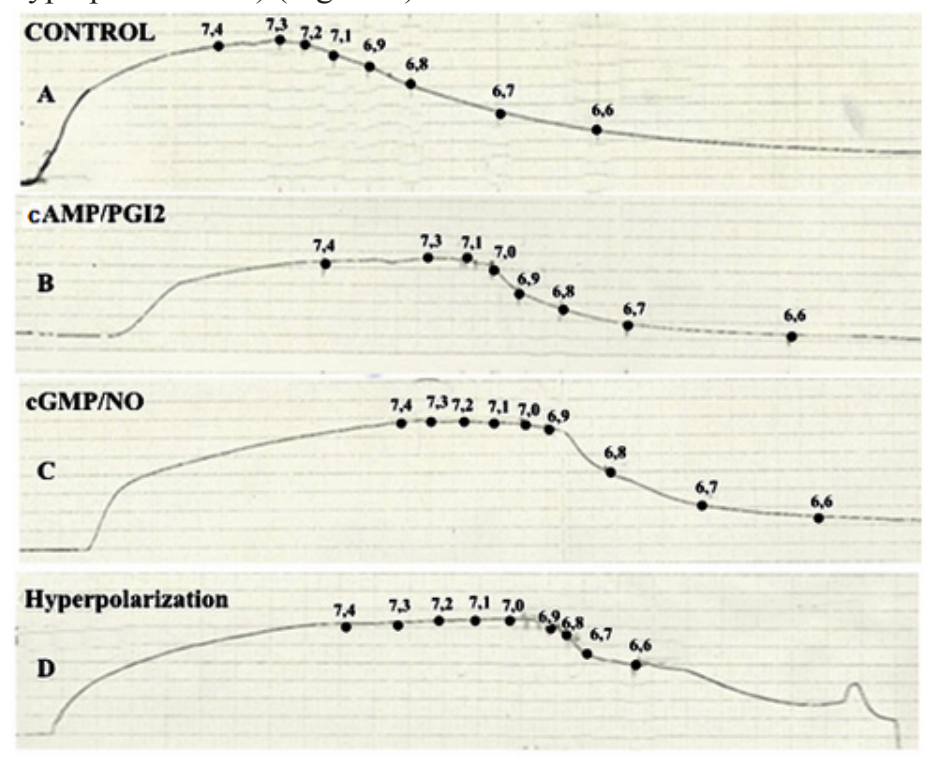

FIGURE 4 - pH response curves induced by bubbling $\mathrm{O}_{2} 60 \% /$ $\mathrm{CO}_{2}$ in vessels (rat aorta) with endothelium pre-contracted with Phenylephrine $\left(10^{-6} \mathrm{M}\right)$. A. Control vessel; B. Presence of Indomethacin $\left(10^{-6} \mathrm{M}\right)$ (phosphodiesterase blocker) in the organ bath; C. Presence of L-NAME $\left(10^{-4} \mathrm{M}\right)$ (NO synthase blocker) in the organ bath, and; D. Presence of tetraethylammonium $\left(10^{-3} \mathrm{M}\right)$ (potassium channel blocker) in the organ bath.

\section{Discussion}

The mechanisms by which $\mathrm{pH}$ influences vascular tone or their response to specific agonists are not yet fully understood, but there is some evidence to suggest the involvement of nitric oxide $(\mathrm{NO})$, prostacyclin $\left(\mathrm{PGI}_{2}\right)$, channels for potassium and calcium flux ${ }^{3}$.

Isolated vessel techniques were used in this study. Thus, the influences of the local control mechanisms (such as shear stress) and neurohumoral tone were eliminated by ensuring that the vascular responses observed could be attributed specifically to acidification $^{3}$.

The literature presents well-designed methods to produce metabolic acidosis in vitro ${ }^{3-5}$. However, methods to induce respiratory acidosis are rare. Stokke et al. ${ }^{5}$ provoked in vitro acidification with different mixtures of oxygen and carbon dioxide, reaching partial $\mathrm{pCO}_{2}$ pressures up to $108 \mathrm{mmHg}$ bubbling a mixture of $18.4 \% \mathrm{CO}_{2} / \mathrm{O}_{2}$ in saline solution and reaching $\mathrm{pH}$ of 6.5. Another study used bubbling anesthetic substances in vitro ${ }^{6}$.

Preliminary results were presented In: Experimental Biology 2014 - FASEB, 2014, San Diego - CA -EUA. Assays were carried out organ baths bubbling the herein mixture of $\mathrm{CO}_{2} /$ 
$(40 \%) / 02(60 \%)$, for the construction of $\mathrm{pH}$-response curves ( $\mathrm{pH}$ 7.4 at 6:6) registering in isometric pre-aortic rings contracted with phenylephrine $\left(10^{-6} \mathrm{M}\right)$. As main results: 1) Relaxations were seen only in endothelial rings; 2) Endothelium-dependent relaxations were inhibited by incubation for $30 \mathrm{~min}$ with indomethacin (10$5 \mathrm{M})$, L-NAME $\left(10^{-4} \mathrm{M}\right)$ and tetraethylammonium $\left(10^{-3} \mathrm{M}\right)$. These data allow concluding by the suitability of the method and the dependence of endothelial vascular response induced by extracellular respiratory acidosis, including the three known mechanisms of vasodilation: cAMP, cGMP and hyperpolarization ${ }^{7}$.

\section{Conclusions}

The gaseous mixture of $40 \% \mathrm{CO}_{2}$ and $60 \% \mathrm{O}_{2}$ was sufficient to shift the $\mathrm{pH}$ from 7.5 to 6.6 gradually $\left(\mathrm{pCO}_{2}=118.2 / 152.8\right)$. This gas mixture was effective in inducing respiratory acidosis at a speed that made possible the recording of isometric force. Pilot studies demonstrating the effectiveness and reproducibility of the method, which has nowadays been routinely used in the Laboratory of Cardiovascular Research and Endothelium Function from the Department of Surgery and Anatomy, Ribeirao Preto School of Medicine-USP.

\section{References}

1. Rohra DK, Saito SY, Ohizumi Y. Functional role of Cl- channels in acidicpH-induced contraction of the aorta of spontaneously hypertensive and WistarKyoto rats. Eur J Pharmacol. 2002 Oct 25;453(2-3):279-86. PMID: 12969757.

2. Rohra DK, Saito SY, Ohizumi Y. Strain-specific effects of acidic $\mathrm{pH}$ oncontractile state of aortas from Wistar and Wistar Kyoto rats. Eur J Pharmacol. 2003 Aug 22;476(1-2):123-30. PMID: 12398916.

3. Celotto AC, Capellini VK, Baldo CF, Dalio MB, Rodrigues AJ, Evora PR. Effects of acid-base imbalance on vascular reactivity. Braz J Med Biol Res. 2008 Jun;41(6):439-45. PMID: 18592120.
4. Celotto AC, Restini CB, Capellini VK, Bendhack LM, Evora PR. Acidosis induces relaxation mediated by nitric oxide and potassium channels in rat thoracic aorta. Eur J Pharmacol. 2011 Apr 10;656(13):88-93. doi: 10.1016/j.ejphar.2011.01.053.

5. Stokke DB, Andersen PK, Brinkløv MM, Nedergaard OA, Hole P, Rasmussen NJ. Acid-base interactions with noradrenaline-induced contractile response of the rabbit isolated aorta. Anesthesiology. 1984 May;60(5):400-4. PMID: 6424511.

6. Blaise G, Sill JC, Nugent M, Van Dyke RA, Vanhoutte PM. Isoflurane causes endothelium-dependent inhibition of contractile responses of canine coronary arteries. Anesthesiology. 1987 Oct;67(4):513-7. PMID: 3662080.

7. Augusto V, Nadai TR; Silveira AP, Albuquerque AA, Vento D, Rodrigues AJ, Celotto AC, Evora PR. In vitro (organ chambers) effects caused by respiratory acidosis on vascular reactivity of the rat aorta (695.6). FASEB J April 2014 28:695.6 (Abstract)

\section{Correspondence:}

Paulo Roberto Barbosa Evora

Departamento de Cirurgia e Anatomia

Faculdade de Medicina de Ribeirão Preto-USP

Avenida Bandeirantes, 3900

14048-900 Ribeirão Preto - SP Brasil

Tel/Fax: (55 16)3602-2497

prbevora@fmrp.usp.br

Received: June 23, 2014

Review: Aug 25, 2014

Accepted: Sep 24, 2014

Conflict of interest: none

Financial sources: Sao Paulo Research Foundation (FAPESP), National Council of Scientific and Technological Development (CNPq), Coordination of Improvement of Higher Academic Staff (CAPES)

${ }^{1}$ Research performed at Laboratory of Cardiovascular and Endothelium Function, Ribeirao Preto School of Medicine, University of Sao Paulo (FMRP-USP), Ribeirao Preto-SP, Brazil. Part of PhD degree thesis, Experimental Medicine Program. Tutor: Paulo Roberto Barbosa Evora. 